\title{
Effect of phylloquinone supplementation on biochemical markers of vitamin $K$ status and bone turnover in postmenopausal women
}

\author{
Susanne Bügel ${ }^{1}$, A. Dorthe Sørensen ${ }^{1}$, Ole Hels ${ }^{1}$, Mette Kristensen ${ }^{1}$, Cees Vermeer ${ }^{2}$, Jette Jakobsen ${ }^{3}$, \\ Albert Flynn $^{4}$, Christian Mølgaard ${ }^{1}$ and Kevin D. Cashman ${ }^{4}$ \\ ${ }^{1}$ Department of Human Nutrition/Centre for Advanced Food Studies, The Royal Veterinary and Agricultural University, \\ Rolighedsvej 30, DK-1958 Frederiksberg C, Denmark \\ ${ }^{2}$ Department of Biochemistry, University of Maastricht, Maastricht, The Netherlands \\ ${ }^{3}$ Danish Institute for Food and Veterinary Research, Søborg, Denmark \\ ${ }^{4}$ Department of Food and Nutritional Sciences, University College Cork, Cork, Republic of Ireland
}

(Received 13 December 2005 - Revised 11 April 2006 - Accepted 24 April 2006)

\begin{abstract}
While current intakes of phylloquinone (vitamin $\mathrm{K}_{1}$ ) in many populations are believed to be sufficient to maintain normal blood coagulation, these may be insufficient to cover the requirements for optimal bone metabolism. Therefore, the objective of the present study was to investigate the effect of increasing phylloquinone intakes above the usual dietary intake for 6 weeks on biochemical markers of vitamin K status and bone turnover in postmenopausal women. Thirty-one postmenopausal women completed this $3 \times 6$-week randomised cross-over study, in which volunteers were supplemented with 0 (placebo), 200, and $500 \mu \mathrm{g}$ phylloquinone/d. In addition, the volunteers were given $10 \mu \mathrm{g}$ vitamin $\mathrm{D}_{3} / \mathrm{d}$ throughout the study period. With increasing phylloquinone intake, the concentration of serum $\gamma$-carboxylated and under- $\gamma$-carboxylated osteocalcin was significantly increased and decreased, respectively, in a dose-dependent manner $(P<0 \cdot 001)$. Mean serum phylloquinone concentration was significantly $(P<0 \cdot 001)$ higher with daily supplementation with $500 \mu \mathrm{g}$ phylloquinone/d compared with that during either of the placebo or $200 \mu \mathrm{g}$ phylloquinone/d supplementation periods, which did not differ $(P=0 \cdot 15)$. Serum total osteocalcin was significantly $(P<0 \cdot 001)$ increased in response to daily supplementation with 500 (but not 200) $\mu \mathrm{g}$ phylloquinone compared with placebo. Serum bone-specific alkaline phosphatase as well as the urinary markers of bone resorption ( $\mathrm{N}$-telopeptide cross-links of collagen, pyridinoline and deoxypyridinoline) and urinary $\gamma$-carboxyglutamate were unaffected by phylloquinone supplementation. In conclusion, while daily supplementation with 200 and $500 \mu \mathrm{g}$ phylloquinone/d for 6 weeks increased vitamin $\mathrm{K}$ status in postmenopausal women, it had no effect on bone turnover.
\end{abstract}

Bone biochemical markers: Phylloquinone supplementation: Vitamin K status: Postmenopausal women: Osteocalcin

Vitamin $\mathrm{K}$ is an essential cofactor for the carboxylation of glutamic acid residues into $\gamma$-carboxyglutamate (Gla) in a limited number of proteins, including plasma prothrombin, plasma pro-coagulants (coagulation factors VII, IX and X) and anticoagulants (proteins $\mathrm{C}$ and $\mathrm{S}$ ), which participate in the coagulation cascade (Shearer, 2000; Institute of Medicine, 2001). In addition, there has been considerable interest in the role of vitamin $\mathrm{K}$ in bone metabolism and bone health since the identification of Gla-containing proteins in bone, notably osteocalcin and matrix Gla protein (Binkley \& Suttie, 1995; Institute of Medicine, 2001; Weber, 2001; Bügel, 2003). The dietary reference value for phylloquinone intake of $1 \mu \mathrm{g} / \mathrm{kg}$ per $\mathrm{d}$ was based on the maintenance of plasma prothrombin concentration (Department of Health, 1991). However, it has been suggested that the dietary vitamin $\mathrm{K}$ intakes needed to maintain normal blood coagulation may be insufficient to cover the requirements for optimal bone metabolism and may thus be suboptimal for bone health (Vermeer et al. 1996; Shearer, 2000). In the USA, the recommendation for vitamin $\mathrm{K}$ intake has recently been revised upwards, with the Food and Nutrition Board establishing an adequate intake of 90 and $120 \mu \mathrm{g}$ phylloquinone/d for women and men, respectively (Institute of Medicine, 2001). A typical European diet is estimated to contain between 80 and $250 \mu \mathrm{g}$ phylloquinone/d on average (Schurgers et al. 1999; Thane et al. 2002), which is sufficient to cover the hepatic requirement for the maintenance of normal haemostasis. While the liver has been shown to be the primary target tissue for vitamin $\mathrm{K}$ when phylloquinone intakes are low, other tissues in addition accumulate vitamin $\mathrm{K}$ at higher intakes (Ronden et al. 1998). It is likely, therefore, that intakes well above current recommendations are required for adequate carboxylation of extrahepatic Gla proteins (Vermeer \& Braam, 2001).

\footnotetext{
Abbreviations: BAP, bone-specific alkaline phosphatase; BMD, bone mineral density; cOC, $\gamma$-carboxylated osteocalcin; Dpyr, deoxypyridinoline; Gla, $\gamma$-carboxyglutamate; NTx, type I collagen cross-linked N-telopeptides; 25(OH)D, 25-hydroxyvitamin D; 1,25(OH) 2 D, 1,25-dihydroxyvitamin D; Pyr, pyridinoline; tOC, total osteocalcin; ucOC, under- $\gamma$-carboxylated osteocalcin.

* Corresponding author: Associate Professor Susanne Bügel, fax +45 35282483, email shb@kvl.dk
} 
The circulating concentration of under-(-carboxylated osteocalcin (ucOC), a sensitive marker of vitamin $\mathrm{K}$ nutritional status (Sokoll \& Sadowski, 1996), has been reported to be a marker of hip fracture risk (Szulc et al. 1993; Vergnaud et al. 1997; Booth et al. 2000) and a predictor of bone mineral density (BMD) and bone turnover (Szulc et al. 1994; Institute of Medicine, 2001; Weber, 2001). Moreover, the findings of two large prospective cohort studies, the Nurses' Health Study (Feskanich et al. 1999) and the Framingham Heart Study (Booth et al. 2000), support an association between relative risk of hip fracture and vitamin $\mathrm{K}$ intake. Booth et al. (2003) reported that adult women (from the Framingham Heart Study) in the lowest quartile of vitamin $\mathrm{K}$ intake $(<70 \mu \mathrm{g} / \mathrm{d})$ had significantly lower $(P<0.005)$ mean BMD than did those in the highest quartile of vitamin $\mathrm{K}$ intake $(309 \mu \mathrm{g} / \mathrm{d})$, an association which was not evident in men. However, one consistent criticism of such epidemiological data is the difficulty in excluding a confounding effect of overall poor nutrition rather than a specific deficit of vitamin K (Binkley \& Suttie, 1995). Furthermore, the mechanism of action of vitamin K on BMD and fracture remains unclear. Booth et al. (2001) showed that $15 \mathrm{~d}$ of dietary vitamin $\mathrm{K}$ depletion led to an increased rate of bone turnover as assessed by serum total osteocalcin (tOC) and urinary type I collagen cross-linked N-telopeptides (NTx); these markers were subsequently normalised by $10 \mathrm{~d}$ of phylloquinone repletion (about $200 \mu \mathrm{g} / \mathrm{d}$ ). Binkley et al. (2000) showed that supplementation with $1 \mathrm{mg}$ phylloquinone for 2 weeks reduced serum tOC but did not alter other markers of bone turnover. Phylloquinone supplementation for 3 years (co-administered with minerals and vitamin D) has been shown to reduce postmenopausal bone (femoral neck) loss, but had no effect on markers of bone turnover (Braam et al. 2003). Therefore, further research on the influence of vitamin $\mathrm{K}$ intake on bone turnover is warranted.

Thus, the aim of the present study was to investigate the effects of increasing the phylloquinone intake, above the usual dietary intake, for 6 weeks on various markers of vitamin $\mathrm{K}$ status, including $\gamma$-carboxylated osteocalcin (cOC) and $\mathrm{ucOC}$, as indices of bone vitamin $\mathrm{K}$ requirements, as well as on biochemical markers of bone turnover in postmenopausal women.

\section{Materials and methods}

\section{Subjects}

Forty-eight postmenopausal women $(>5$ years since last menses) were recruited from the area of Copenhagen through advertising in local newspapers, posters and letters through the Danish Civil Registration System, of which thirty-one completed all three intervention periods. The seventeen subjects that dropped out of the study did so for personal reasons not related to the study. None of the subjects took dietary supplements, other than prescribed by the study, during and for at least 2 months before the beginning of the study. None of the recruited subjects performed excessive physical activity. Other exclusion criteria included smoking, hormone replacement therapy, chronic illness, and drugs known to affect vitamin $\mathrm{K}$ status or $\mathrm{Ca}$ or bone metabolism. All subjects were given a brief medical examination at recruitment by a physician.

\section{Ethical considerations}

The research protocol was approved by the Municipal Ethical Committee of Copenhagen and Frederiksberg (KF no. 01-104/ $00)$, and a written consent was obtained from each subject.

\section{Experimental design}

The study was performed as a supplementation study in freeliving subjects and consisted of a randomised cross-over trial of three successive intervention periods, each of 6 weeks, with intervening 3-week washout periods. The total duration of the study was 24 weeks from August to February. In the washout periods, the subjects consumed their usual diets and were instructed not to change their diet throughout the study period. The regimens were 'placebo' (usual diet plus $0 \mu \mathrm{g}$ phylloquinone/d), '200 $\mu \mathrm{g}$ phylloquinone supplemented' (usual diet plus $200 \mu \mathrm{g}$ phylloquinone/d) or ' $500 \mu \mathrm{g}$ phylloquinone supplemented' (usual diet plus $500 \mu \mathrm{g}$ phylloquinone/d). The subjects were instructed to return the glass with tablets, and compliance was determined by counting the remaining tablets. In addition, each subject was supplemented throughout the study period with $10 \mu \mathrm{g}$ vitamin $\mathrm{D}_{3} / \mathrm{d}$, commencing 2 months before the first intervention, so as to avoid seasonal changes in vitamin D status. Phylloquinone-containing (200 or $500 \mu \mathrm{g})$ and matching placebo tablets (F Hoffmann-LaRoche Ltd, Basel, Switzerland) were given daily (in a double-blinded fashion) from day 1 to day 42 in each intervention period. Blood and urine samples were collected at the initiation of the study (baseline measurements) and at the end of each intervention period (see later).

\section{Dietary analysis}

Usual dietary intakes of $\mathrm{Ca}, \mathrm{P}$ and protein were estimated by a validated food-frequency questionnaire (Mølgaard et al. 1998). Questionnaires were mailed to the subjects and returned before the intervention study began.

\section{Bone mineral density}

BMD of the postero-anterior lumbar spine (L2-L4) and total hip (femoral neck, trochanter and intertrochanter) was measured using a LUNAR DPX-IQ scanner (Lunar Corporation Ltd, Madison, WI, USA). Standardised positioning and utilisation of the software was used. The scans were acquired using the pencil-beam mode and they were analysed using Lunar software version $4.6 \mathrm{c}$ using the compare feature.

\section{Urinary specimens}

From days 1-3 and 40-42 for each intervention period, $24 \mathrm{~h}$ urine was collected in acid-washed plastic bottles containing 1 $\mathrm{M}^{-} \mathrm{HNO}_{3}(10 \mathrm{ml})$. Collection of urine on all urine-sampling days entailed collection of the first morning void sample and the following $24 \mathrm{~h}$ sample separately. The start time of the collection was not standardised but the first morning void was noted daily. To ensure complete collection of urine, $p$-aminobenzoic acid tablets $(3 \times 80 \mathrm{mg} / \mathrm{d}$; local pharmacy of The Royal Veterinary and Agricultural University (KVL), 
Frederiksberg, Denmark) were given on days of urine collection, as described elsewhere (Bingham \& Cummings, 1983).

\section{Blood samples}

Blood samples were drawn at the beginning and end of each intervention period. The participants were asked to fast for $12 \mathrm{~h}$ and abstain from severe physical activity, intake of any kind of drugs for $48 \mathrm{~h}$, and from alcohol for $24 \mathrm{~h}$ before sampling. Samples were collected in the morning (08.0010.00 hours). Blood samples were processed to serums or plasma and stored at -20 and $-80^{\circ} \mathrm{C}$, as appropriate, until required for analysis. $\mathrm{Hb}$ was measured in a whole-blood sample on the day of blood collection.

For a number of blood and urine analyses, all samples from one individual were measured in one run, and thus no interassay variation is given.

\section{Serum phylloquinone, carboxylated and undercarboxylated osteocalcin}

Serum phylloquinone concentrations were assessed by HPLC and fluorescence detection (excitation $244 \mathrm{~nm}$, emission $430 \mathrm{~nm}$ ) after on-line electrochemical reduction of the effluent (Gijsbers et al. 1996; Schurgers et al. 1999). In short, a $0.5 \mathrm{ml}$ sample was supplemented with $0.5 \mathrm{ml}$ distilled water, $2 \mathrm{ml}$ ethanol and $1 \mathrm{ng}$ internal standard (2,3-dihydrophylloquinone; F Hoffmann-LaRoche Ltd, Basel, Switzerland) and extracted with $4 \mathrm{ml}$ hexane. After centrifugation for $2 \mathrm{~min}$ at $2000 \mathrm{~g}$ the hexane phase was removed, evaporated under a stream of $\mathrm{N}_{2}$ gas, and the residue was redissolved in $2 \mathrm{ml}$ hexane. Pre-purification of the sample was performed with silica sep-pack cartridges (Millipore Corp., Milford, MA, USA) before analysis on a BDS Hypersil C18 column (ThermoHypersil-Keystone; Thermo Electron Corp., Bellefonte, PA, USA). Both ucOC and cOC were measured with a sandwich ELISA based on a monoclonal antibody against tOC as a capture antibody and conformation-specific antibodies as second antibodies for ucOC and cOC, respectively (Glu-OC and Gla-OC test kit; Takara Shuzo Corp., Tokyo, Japan). The Gla residues are located at positions 17, 21 and 24 and not directly at the $\mathrm{N}$ terminus, thus large degradation products missing the $\mathrm{N}$ terminus may also be detected. The specificity for the respective conformations is high with less than $5 \%$ cross-reaction. The intra-assay and inter-assay $\mathrm{CV}$ for cOC analysis were 3.5 and $4.5 \%$, respectively. The intra-assay and inter-assay $\mathrm{CV}$ for ucOC analysis were 5 and $6 \%$, respectively. The assay $\mathrm{CV}$ for the ucOC:cOC ratio was $11 \%$.

\section{Serum 25-hydroxyvitamin D}

Serum proteins were precipitated with ethanol, and deprotein ised serum was subsequently applied to a MFC18 solid-phase extraction column (Isolute ${ }^{\circledR}$; International Sorbent Technology Ltd, Pontypridd, Mid Glamorgan, UK) for elution of the serum 25-hydroxyvitamin D $(25(\mathrm{OH}) \mathrm{D})$ fraction with ethyl acetate:n-heptane (10:90). The extracted 25(OH)D was injected onto an HPLC-system (Waters Corp., Milford, MA, USA) equipped with a 600 controller and pump, a refrigerated $717_{\text {PLUs }}$ Autosampler, a 996 diode array detector (set at 220$320 \mathrm{~nm}$ ) for detection, and a 2487 absorbance detector (set at
$265 \mathrm{~nm}$ ) for quantification. The HPLC column used for separation was a cyano (Luna; Phenomenex Inc., Torrance, CA, USA) in which $25(\mathrm{OH}) \mathrm{D}_{2}$ and $25(\mathrm{OH}) \mathrm{D}_{3}$ was eluted separately with 2-propanol:n-heptane (1.5:98.5). However, none of the samples contained $25(\mathrm{OH}) \mathrm{D}_{2}$. Samples were analysed in duplicate on different days, showing a CV of $6.0 \%$. The accuracy of the analysis was monitored by participation in the Vitamin D External Quality Assessment Scheme (DEQAS; Charing Cross Hospital, London, UK).

\section{Serum 1,25-dihydroxyvitamin D}

A RIA (no. 65100E; DiaSorin Ltd, Stillwater, MN, USA) was used for the quantification of serum 1,25-dihydroxyvitamin D $\left(1,25(\mathrm{OH})_{2} \mathrm{D}\right)$ levels. The manufacturer's method was modified slightly as solid-phase extraction was performed on MFC18 columns (Isolute ${ }^{\circledR}$; International Sorbent Technology Ltd). Samples were analysed in duplicate on different days, showing an inter-assay CV of $12.6 \%$. The accuracy of the analysis was monitored by participation in the Vitamin D External Quality Assessment Scheme (Charing Cross Hospital, London, UK).

\section{Plasma parathyroid hormone}

Plasma samples were analysed in duplicate for intact parathyroid hormone with a chemiluminescent immunometric assay (IMMULITE ${ }^{\circledR}$; Diagnostic Products Corp., Los Angeles, CA, USA). The intra-assay CV for this assay was $5.8 \%$, while inter-assay variation was $10 \%$.

\section{Serum total osteocalcin and bone-specific alkaline phosphatase}

Serum tOC levels were measured in serum samples using an ELISA (BRI-Diagnostics Ltd, Dublin, Republic of Ireland). The intra-assay $\mathrm{CV}$ has been measured as $3.7 \%$. Serum bone-specific alkaline phosphatase (BAP) levels were measured in serum samples using a recently developed ELISA (Alkphase- ${ }^{\mathrm{TM}}$; MetraBiosystems Ltd, Wheatley, Oxon, UK). The intra-assay $\mathrm{CV}$ has been measured as $4.5 \%$.

\section{Haemoglobin and serum $\alpha_{1}$-antichymotrypsin}

$\mathrm{Hb}$ was analysed in whole-blood samples by photometric absorption measurements with sodium lauryl sulfate as the haemolysing agent on a Sysmex KX-21 apparatus (Sysmex Corp., Kobe, Japan). The intra-assay CV for this assay was $0.5 \%$ ( $n$ 12) and the inter-assay CV was $0.6 \%$ ( $n$ 27). Serum $\alpha_{1}$-antichymotrypsin was measured by turbidimetric detection of antigen-antibody reaction on Cobas Mira apparatus (Roche Diagnostic Systems, F Hoffmann-La Roche Ltd, Basel, Switzerland) using rabbit antihuman $\alpha_{1}$-antichymotrypsin (DAKO, Glostrup, Denmark). The intra-assay CV for this assay was $2 \cdot 1 \%(n 12)$ and the inter-assay CV was $4 \cdot 19 \%(n 79)$.

\section{Urinary free $\gamma$-carboxyglutamate}

Free Gla was analysed in $24 \mathrm{~h}$ urine samples using the procedure developed by Kuwada \& Katayama (1983). In short, the urine samples were diluted with distilled water 
and analysed by HPLC, using a Nucleosil 100-5 SB anion exchange resin ( $5 \mu \mathrm{m}$ particles; Macherey-Nagel, $\mathrm{GmbH} \&$ Co. KG, Düren, Germany) at a flow rate of $1 \mathrm{ml} / \mathrm{min}$. Reference curves were prepared from samples with known concentration of authentic Gla (Sigma-Aldrich Corp., St Louis, MO, USA). The inter-assay CV was $5 \%$.

\section{Urinary pyridinoline and deoxypyridinoline}

The morning urine samples (first morning void) were analysed in triplicate for urinary pyridinoline (Pyr) and deoxypyridinoline (Dpyr) using a three-step procedure. Urine was firstly hydrolysed with an equal volume of $12 \mathrm{M}-\mathrm{HCl}$ at $100^{\circ} \mathrm{C}$ for $18 \mathrm{~h}$. The cross-links were then extracted by $\mathrm{CF} 1$ cellulose chromatography with the use of an internal standard (acetylated Pyr; MetraBiosystems Ltd, Wheatley, Oxon, UK) and the samples were analysed using reversed-phase HPLC with fluorescence detection (Colwell et al. 1993). The acetylated Pyr was applied in accordance with the method described by Calabresi et al. (1994) and Robins et al. (1994). The content of cross-links in the urine was quantified by external standardisation using a commercially available Pyr/Dpyr HPLC calibrator (MetaBiosystems Ltd, Wheatley, Oxon, UK). The intra-assay $\mathrm{CV}$ for Pyr and Dpyr measured as the variation between ten chromatograms obtained between column regenerations as described by Colwell et al. (1993) have previously been measured as 6 and $7 \%$, respectively.

\section{Urinary creatinine}

Creatinine was determined in the morning urine samples (first morning void) using a diagnostic kit (Metra Creatinine Assay Kit; Quidel Corp., San Diego, CA, USA). The intra-assay CV was $1.6 \%$.

\section{Urinary type I collagen cross-linked N-telopeptides}

NTx were measured in the morning urine samples (first morning void) by an ELISA (Osteomark ${ }^{\circledR}$; Ostex International Inc., Seattle, WA, USA). The intra-assay $\mathrm{CV}$ was $5 \%$.

\section{Statistical analyses}

All analyses and calculations were performed using the Statistical Analysis System software package, version 8.2 (SAS Institute, Cary, NC, USA). Univariate mixed model analyses of covariance (ANCOVA) were performed in the 'MIXED' procedure with Tukey's post hoc test. In the statistical model, biochemical markers were evaluated as the dependent variable. Treatment, order and treatment $\times$ order were included as independent fixed variables and baseline values as covariates. Subjects were included as a random effect. In models with significant treatment $\times$ order (phylloquinone, cOC, and BAP), the interaction was adjusted for by including the preceding value at each period as covariate.

Denoting the $i$ th subject's $(1,2, \ldots, 31) j$ th dependent variable (serum phylloquinone, $25(\mathrm{OH}) \mathrm{D}, 1,25(\mathrm{OH})_{2} \mathrm{D}$, tOC, ucOC, cOC, ucOC:cOC, and BAP, and urinary NTx, Pyr, Dpyr, and Gla) in period $t$ (0 (baseline), 1, 2, 3), the statistical models with significant treatment $\times$ order were as follows:

$$
\begin{aligned}
Y_{i j t}= & \text { treatment }_{i j t}+\text { order }_{i j t}+\text { treatment } \times \operatorname{order}_{i j t}+\alpha\left(Y_{i j, t=0}\right) \\
& +\beta\left(Y_{i j, t-1}\right)+\delta_{i}+\varepsilon_{i j t},
\end{aligned}
$$

where $\delta$ s are subject-specific random effects and $\varepsilon s$ are independently distributed random variables.

Homogeneity of variance and normal distribution among random effects were investigated by plots of residuals. Shapiro-Wilk's test for normal distribution was performed. The investigations showed it necessary to log-transform all dependent biochemical variables, except serum phylloquinone (which was transformed by square root), tOC, cOC and BAP. Where necessary, transformed data were back-transformed, and data are presented as means and SD or means and SEM where appropriate.

\section{Results}

\section{Descriptive data}

Baseline anthropometric data as well as baseline $\mathrm{Hb}$, ferritin and $\alpha_{1}$-antichymotrypsin, and BMD measurements of the postmenopausal women who participated in the study are shown in Table 1. All women were of average height and weight for their age group. None of the postmenopausal women were suffering from Fe deficiency. Mean $\mathrm{Hb}$ concentration was $7.9(\mathrm{SD} 0.4) \mathrm{mmol} / \mathrm{l}$ (range $7.2-8.7 \mathrm{mmol} / \mathrm{l}$; 95th percentile $8.6 \mathrm{mmol} / \mathrm{l}$ ) and mean ferritin concentration was 107.1 (SD 130.4) $\mu \mathrm{g} / \mathrm{l}$ (range 11.4-621.2 $\mu \mathrm{g} / \mathrm{l}$; 95th percentile $348.9 \mu \mathrm{g} / \mathrm{l})$. The mean concentration of serum $25(\mathrm{OH}) \mathrm{D}$ at baseline was 58 (SD 18) nmol/l, and the mean plasma

Table 1. Subject characteristics

\begin{tabular}{|c|c|c|}
\hline & \multicolumn{2}{|c|}{$\begin{array}{c}\text { Postmenopausal } \\
\text { women }(n 31)\end{array}$} \\
\hline & Mean & SD \\
\hline Age (years) & 62.5 & $4 \cdot 0$ \\
\hline Weight (kg) & $71 \cdot 3$ & $9 \cdot 7$ \\
\hline Height (m) & 1.65 & 0.06 \\
\hline BMI $\left(\mathrm{kg} / \mathrm{m}^{2}\right)$ & $26 \cdot 1$ & $3 \cdot 0$ \\
\hline $\mathrm{Hb}(\mathrm{mmol} / \mathrm{l})$ & 7.9 & 0.4 \\
\hline Ferritin $(\mu \mathrm{g} / \mathrm{l})$ & $107 \cdot 0$ & $130 \cdot 4$ \\
\hline Serum $\alpha$-antichymotrypsin $(g / l)$ & 0.31 & 0.06 \\
\hline \multicolumn{3}{|l|}{ Baseline bone mineral density* } \\
\hline Spine $\left(\mathrm{g} / \mathrm{cm}^{2}\right)$ & $1 \cdot 114$ & 0.162 \\
\hline T-score & -0.68 & $1 \cdot 34$ \\
\hline Femur $\left(\mathrm{g} / \mathrm{cm}^{2}\right)$ & 0.925 & $0 \cdot 116$ \\
\hline T-score & -0.53 & 1.03 \\
\hline \multicolumn{3}{|l|}{ Dietary intake } \\
\hline Total Ca $(\mathrm{mg} / \mathrm{d})$ & 696 & 401 \\
\hline Ca from dairy products (mg/d) & 552 & 347 \\
\hline Total P $(\mathrm{mg} / \mathrm{d})$ & 961 & 412 \\
\hline Total protein $(\mathrm{g} / \mathrm{d})$ & 52 & 20 \\
\hline Protein from meat $(\mathrm{g} / \mathrm{d})$ & 16 & 10 \\
\hline \multicolumn{3}{|c|}{$\begin{array}{l}\text { * Diagnostic criteria for osteoporosis and osteopenia, based on } \\
\text { bone mineral density, include: normal, more than }-1 \text { SD of } \\
\text { young adult reference mean for the population; osteopenia, } \\
\text { between }-1 \text { and }-2.5 \text { SD of the young adult mean; osteoporo- } \\
\text { sis, more than }-2.5 \mathrm{SD} \text { below the young adult mean (World } \\
\text { Health Organization, 1994). }\end{array}$} \\
\hline
\end{tabular}
(Mean values and standard deviations) 
parathyroid hormone concentration was $5 \cdot 3$ (SD 1.6) pmol/1. The overall mean concentration of the acute-phase protein $\alpha_{1}$-antichymotrypsin was 0.30 (SD 0.05 ) g/l (range $0.21-$ $0.49 \mathrm{~g} / \mathrm{l} ; 95$ th percentile $0.38 \mathrm{~g} / \mathrm{l}$ ) during the entire intervention study and the mean recovery of $p$-aminobenzoic acid tablets was 100 (SD 25) \%. Fifteen of the thirty-one women who completed the study had low bone density (thirteen had osteopenia and two had osteoporosis, as indicated by T-score) at the spine and/or femur. Habitual dietary intakes of $\mathrm{Ca}, \mathrm{P}$ and protein, as recorded by food-frequency questionnaires, are shown in Table 1. Of the glasses with tablets, $48 \%$ were returned; based on these, compliance was determined to be 98.9 (SD 1.9) $\%$.

\section{Effect of phylloquinone supplementation on markers of vitamin $K$ status}

The effects of phylloquinone supplementation on vitamin $\mathrm{K}$ status markers are shown in Table 2. No significant difference in mean serum phylloquinone concentration was observed between the placebo and the $200 \mu \mathrm{g} / \mathrm{d}$ phylloquinone supplementation period $(P=0 \cdot 15)$. However, mean serum phylloquinone concentration during the $500 \mu \mathrm{g}$ phylloquinone/d supplementation period was significantly $(P<0.001)$ higher than that during either of the other two intervention periods. There was a significant $(P<0.001)$ dose-dependent increase and decrease in serum cOC and ucOC concentrations, respectively, with increasing phylloquinone intake in postmenopausal women. A corresponding significant $(P<0.001)$ decrease in the serum ucOC:cOC ratio was revealed with increasing phylloquinone intake. The reduction in ucOC:cOC ratio was shown to be 62 and $94 \%$ after supplementation with 200 and $500 \mu \mathrm{g}$ phylloquinone/d, respectively. Correspondingly, a 27 and $81 \%$ increase in serum phylloquinone concentration was seen after supplementation with 200 and $500 \mu \mathrm{g}$ phylloquinone/ d, respectively (Table 2). Urinary Gla concentration was unaffected by phylloquinone supplementation.
Effect of phylloquinone supplementation on biochemical markers of bone turnover

The effects of phylloquinone supplementation on biochemical markers of bone turnover in postmenopausal women are shown in Table 3. Phylloquinone supplementation had no effect on urinary Pyr, Dpyr or NTx concentration (all expressed per mmol creatinine). Similarly, phylloquinone supplementation had no effect on serum BAP, $25(\mathrm{OH}) \mathrm{D}$ or $1,25(\mathrm{OH})_{2} \mathrm{D}$ or plasma parathyroid hormone concentrations. While there was no significant difference in mean serum tOC concentration between the placebo and the $200 \mu \mathrm{g} / \mathrm{d}$ phylloquinone supplementation period, mean serum tOC concentration during the $500 \mu \mathrm{g} / \mathrm{d}$ phylloquinone supplementation period was significantly $(P<0 \cdot 001)$ higher than that during the placebo intervention period. However, there was no significant difference in serum tOC concentration between the two phylloquinone-supplemented periods.

\section{Discussion}

The postmenopausal women who participated in the present study were non-anaemic, well nourished and apparently healthy according to the $\alpha_{1}$-antichymotrypsin measurement. The recorded mean dietary intake of $\mathrm{Ca}$ in the present study was lower than recommended in the USA for this age group but above the lower limit for recommended intake of $\mathrm{Ca}$ in Denmark (Institute of Medicine, 1997; Becker et al. 2004). However, the $\mathrm{Ca}$ intake was lower than expected, and thus Ca supplementation was not provided together with the daily vitamin D supplementation.

The serum concentration of ucOC obtained after placebo treatment would suggest that subclinical vitamin K deficiency was relatively common in these postmenopausal women, in agreement with the findings of others (Knapen et al. 1989; Plantalech et al. 1990; Binkley et al. 2000). Whether this insufficiency has physiological or clinical relevance is unclear. However, the degree of undercarboxylation seen in the present study (30\% ucOC in the placebo period) is not uncommon.

Table 2. Effect of vitamin $K_{1}$ supplementation in addition to $10 \mu \mathrm{g}$ vitamin $\mathrm{D} / \mathrm{d}$ for 6 weeks on vitamin $\mathrm{K}$ status markers in postmenopausal women ( $n 31)^{*}$

(Mean values with their standard errors)

\begin{tabular}{|c|c|c|c|c|c|c|}
\hline \multirow[b]{2}{*}{ Intervention } & \multicolumn{2}{|c|}{$\begin{array}{l}\text { Placebo } \\
(0 \mu \mathrm{g} / \mathrm{d})\end{array}$} & \multicolumn{2}{|c|}{$\begin{array}{l}\text { Phylloquinone } \\
\text { supplemented } \\
\text { (200 } \mu \mathrm{g} / \mathrm{d})\end{array}$} & \multicolumn{2}{|c|}{$\begin{array}{c}\text { Phylloquinone } \\
\text { supplemented } \\
(500 \mu \mathrm{g} / \mathrm{d})\end{array}$} \\
\hline & Mean & SEM & Mean & SEM & Mean & SEM \\
\hline \multicolumn{7}{|l|}{ Blood markers } \\
\hline Phylloquinone (nmol/l)† & $2 \cdot 42^{\mathrm{a}}$ & 0.40 & $3.06^{a}$ & 0.40 & $4 \cdot 70^{\mathrm{b}}$ & 0.40 \\
\hline $\operatorname{cOC}(\mu \mathrm{g} / \mathrm{l}) \ddagger$ & $5 \cdot 06^{a}$ & 0.25 & $6 \cdot 84^{b}$ & 0.25 & $7 \cdot 70^{c}$ & 0.25 \\
\hline $\mathrm{ucOC}(\mu \mathrm{g} / \mathrm{l})$ & $3.82^{\mathrm{a}}$ & $0 \cdot 15$ & $2 \cdot 27^{b}$ & $0 \cdot 15$ & $1 \cdot 23^{\mathrm{C}}$ & 0.15 \\
\hline ucOC:cOC & $0.91^{a}$ & 0.05 & $0.35^{\mathrm{b}}$ & 0.05 & $0.17^{c}$ & 0.05 \\
\hline \multicolumn{7}{|l|}{ Urinary markers } \\
\hline Gla $(\mu \mathrm{mol} / \mathrm{d})$ & $26 \cdot 7$ & $5 \cdot 2$ & $29 \cdot 3$ & $5 \cdot 3$ & $32 \cdot 0$ & $5 \cdot 2$ \\
\hline
\end{tabular}

cOC, serum carboxylated osteocalcin; ucOC, serum undercarboxylated osteocalcin; Gla, free $\gamma$-carboxyglutamate.

${ }^{a, b, c}$ Mean values within a row with unlike superscript letters were significantly different $(P<0.001$;

Tukey's honestly significant difference test).

* The presented results were obtained on the last day of the 6-week supplementation period.

$\dagger P_{\text {order } x \text { treatment }}=0.025$ (conversion factor: $\left.\mu \mathrm{g} / \mathrm{l}=0.45 \times \mathrm{nmol} / \mathrm{l}\right)$.

$\ddagger P_{\text {order } x \text { treatment }}=0.032$. 
Table 3. Effect of vitamin $\mathrm{K}_{1}$ supplementation in addition to $10 \mu \mathrm{g}$ vitamin $\mathrm{D} / \mathrm{d}$ for 6 weeks on circulating parathyroid hormone (PTH), vitamin D metabolites and biochemical markers of bone turnover in postmenopausal women $(n 31)^{*}$

(Mean values with their standard errors)

\begin{tabular}{|c|c|c|c|c|c|c|}
\hline \multirow[b]{2}{*}{ Intervention } & \multicolumn{2}{|c|}{$\begin{array}{l}\text { Placebo } \\
(0 \mu \mathrm{g} / \mathrm{d})\end{array}$} & \multicolumn{2}{|c|}{$\begin{array}{c}\text { Vitamin } \mathrm{K}_{1} \\
\text { supplemented } \\
(200 \mu \mathrm{g} / \mathrm{d})\end{array}$} & \multicolumn{2}{|c|}{$\begin{array}{c}\text { Vitamin } \mathrm{K}_{1} \\
\text { supplemented } \\
(500 \mu \mathrm{g} / \mathrm{d})\end{array}$} \\
\hline & Mean & SEM & Mean & SEM & Mean & SEM \\
\hline \multicolumn{7}{|l|}{ Blood markers } \\
\hline 25(OH)D (nmol/l) & $64 \cdot 2$ & $2 \cdot 3$ & 64.4 & $2 \cdot 3$ & $64 \cdot 1$ & $2 \cdot 3$ \\
\hline $1,25(\mathrm{OH})_{2} \mathrm{D}(\mathrm{pmol} / \mathrm{l})$ & 104 & 5 & 111 & 5 & 107 & 5 \\
\hline PTH $(\mathrm{pmol} / \mathrm{l})$ & 5.09 & 0.24 & $5 \cdot 15$ & 0.24 & $5 \cdot 12$ & 0.24 \\
\hline tOC $(\mu \mathrm{g} / \mathrm{l})$ & $13 \cdot 7^{\mathrm{a}}$ & 0.7 & $14 \cdot 7^{\mathrm{a}, \mathrm{b}}$ & 0.7 & $15 \cdot 7^{b}$ & 0.7 \\
\hline BAP $(U / I) \dagger$ & $24 \cdot 2$ & $0 \cdot 7$ & $24 \cdot 7$ & 0.7 & $24 \cdot 8$ & 0.7 \\
\hline \multicolumn{7}{|l|}{ Urinary markers } \\
\hline Pyr (nmol/mmol Cr) & $23 \cdot 2$ & 1.2 & $22 \cdot 4$ & $1 \cdot 2$ & $23 \cdot 8$ & $1 \cdot 2$ \\
\hline Dpyr (nmol/mmol Cr) & $9 \cdot 1$ & 0.6 & $7 \cdot 8$ & 0.6 & $8 \cdot 6$ & 0.6 \\
\hline NTx (nmol BCE $/ \mathrm{mmol} \mathrm{Cr})$ & $55 \cdot 3$ & 4.0 & $57 \cdot 6$ & 4.0 & 58.5 & $4 \cdot 0$ \\
\hline
\end{tabular}

25(OH)D, serum 25 hydroxyvitamin D; $1,25(\mathrm{OH})_{2} \mathrm{D}$, serum 1,25 dihydroxyvitamin $\mathrm{D}$; tOC, serum total osteocalcin; BAP, serum bone-specific alkaline phosphatase; Pyr, pyridinoline; $\mathrm{Cr}$, creatinine; Dpyr, deoxypyridinoline; NTx, type I collagen cross-linked N-telopeptides; BCE, bone collagen equivalent.

${ }^{a, b}$ Mean values within a row with unlike superscript letters were significantly different $(P<0.001$; Tukey's

honestly significant difference test).

* The presented results were obtained on the last day of the 6-week supplementation period

$\dagger P_{\text {order } x \text { treatment }}=0.003$.

It has ranged from $7.5 \%$ to $50 \%$ in other studies in postmenopausal women, whose estimated intake of phylloquinone was 90-220 $\mu \mathrm{g} / \mathrm{d}$ (Knapen et al. 1989; Plantalech et al. 1990; Booth et al. 1999, 2003; Binkley et al. 2000; McKeown et al. 2002). Possible explanations for this variation in carboxylation degree include the use of different assays in different studies and variation in phylloquinone intake. However, a high serum ucOC concentration has been associated with increased bone turnover (Knapen et al. 1993), low BMD (Szulc et al. 1994) and increased risk of osteoporotic fractures (Szulc et al. 1993, 1996; Vergnaud et al. 1997). If ucOC produces adverse skeletal consequences, increased phylloquinone intake should lower the degree of undercarboxylation of OC as well as benefiting bone turnover, BMD and/or fracture risk.

In the present study, supplementation of the usual diet with additional phylloquinone increased the degree of carboxylation, and consequently decreased the degree of undercarboxylation of OC, in a dose-dependent manner (by 40 and $68 \%$, with 200 and $500 \mu \mathrm{g}$ phylloquinone/d, respectively). This occurred in apparently healthy subjects whose serum phylloquinone concentrations were well within the normal range for healthy women of this age group (Sadowski et al. 1989; Institute of Medicine, 2001). Older healthy subjects appear to have higher serum phylloquinone concentrations than younger subjects regardless of dietary intake (Sokoll \& Sadowski, 1996). As regards the records of vitamin $\mathrm{K}$ intakes, they seem to be wide-ranging, reporting intakes from 50 to $250 \mu \mathrm{g}$ phylloquinone/d (Booth et al. 1999; Schurgers et al. 1999; Thane et al. 2002; Duggan et al. 2004). The dietary assessment tool used in the present study was designed to estimate habitual intakes of $\mathrm{Ca}$, and was not appropriate to estimate habitual dietary phylloquinone intake. Making such an estimate is further complicated by the lack of sufficient data on the phylloquinone content of Danish foods in Danish Food Databases. However, the mean usual dietary intakes of phylloquinone of similarly-aged women ( $n$ 28) were estimated recently using $6 \mathrm{~d}(2 \times 3 \mathrm{~d})$ of food diaries using a Dutch food database as part of a different study (ISOHEART). The mean phylloquinone intake in that study was found to be 189 (SD 182) $\mu \mathrm{g} / \mathrm{d}$ (S Bügel, unpublished results).

Therefore, it seems likely, although not measured, that the Danish women in the present study would have a higher consumption of phylloquinone than that reported in the USA and UK, contributing to relatively high, though within normal range, concentrations of serum phylloquinone (Booth et al. 1999; Institute of Medicine, 2001; Thane et al. 2002; Vermeer et al. 2004). Despite this, the ucOC:cOC ratio shown to be 0.91 in the placebo intervention suggests that the usual dietary intakes of phylloquinone in the present women were inadequate to allow maximal $\gamma$-carboxylation of osteocalcin. Phylloquinone supplementation (ranging from 0 to $1000 \mu \mathrm{g} / \mathrm{d}$ ) for 2 weeks has been shown to dose-dependently decrease $(P<0.001)$ the percentage undercarboxylation of osteocalcin in adult men and women (Binkley et al. 2002). Furthermore, in a second sub-study, the same authors reported that while supplementation with 1000 and $2000 \mu \mathrm{g}$ doses of phylloquinone produced greater reductions in the percentage undercarboxylation of osteocalcin than a $500 \mu \mathrm{g}$ phylloquinone dose, there was no significant difference in the reductions in the percentage undercarboxylation of osteocalcin between the higher doses, suggesting that at least $1000 \mu \mathrm{g}$ phylloquinone is required to maximally $\gamma$-carboxylate osteocalcin (Binkley et al. 2002).

Supplementation with $500 \mu \mathrm{g}$ phylloquinone/d (but not $200 \mu \mathrm{g})$ for 6 weeks significantly increased serum phylloquinone (by about 2-fold) in postmenopausal women in the present study. Phylloquinone supplementation for 1-2 weeks has been shown to significantly increase serum phylloquinone concentration in adults in other studies (Binkley et al. 2000, 2002). On the other hand, urinary Gla concentration did not respond to phylloquinone supplementation over 6 weeks in the present study. Booth et al. (2001) have suggested that urinary Gla, a measure of turnover of all vitamin K-dependent proteins, is less responsive to short-term phylloquinone changes 
than is ucOC, but a lack of responsiveness may also be reflected by the subjects' apparently adequate habitual intake of phylloquinone. Blood lipid levels are also known to influence phylloquinone serum concentrations. However, all subjects who completed the study were within the normal range of both serum triacylglycerol and cholesterol levels (M Kristensen, J Kudsk, S Bügel, unpublished results).

In the present study, there was a modest (about $15 \%$ ) but significant $(P<0.05)$ increase in serum tOC concentration with phylloquinone supplementation adding $500 \mu \mathrm{g}$ phylloquinone/d (but not $200 \mu \mathrm{g} / \mathrm{d}$ ) to the usual diet for 6 weeks. In contrast, supplementation with $1000 \mu \mathrm{g}$ phylloquinone/d was reported to have either no effect in younger and older adults (Knapen et al. 1989, Douglas et al. 1995; Binkley et al. 2002) or result in an observed age-independent decrease in serum tOC concentration (Binkley et al. 2000). It has been suggested that the use of different antibodies to measure tOC in different studies causes the discrepancy in results, which may be an artifact of the variation in affinities of different antibodies for the carboxylated form (Gundberg et al. 1998). There is some evidence that there may be an interaction between vitamin $\mathrm{K}$ and vitamin $\mathrm{D}$ in relation to production of fully functional osteocalcin (Shearer, 1997); however, a potential confounding effect of vitamin D was eliminated in the present study as the subjects were supplemented with vitamin D for 2 months before the study and throughout the study period. The increase in serum tOC with phylloquinone supplementation may have been due to the fully carboxylated OC being secreted more efficiently from the osteoblasts whereas the under- or noncarboxylated species have a tendency to accumulate in the cell (Nishimoto \& Price, 1985; Wu et al. 1996). In support of this, we saw no effect of phylloquinone supplementation on serum BAP concentration. This is in agreement with the findings of Binkley et al. (2000) and Braam et al. (2003), which showed that supplementation with $1 \mathrm{mg}$ phylloquinone for 2 weeks and 3 years, respectively, had no effect on serum BAP. In addition, the findings of the present study show no effect of phylloquinone supplementation for 6 weeks on urinary Pyr, Dpyr and NTx, suggesting a lack of effect on the rate of bone resorption, in agreement with the findings of Binkley et al. (2000). It can be argued that the lack of effect of phylloquinone supplementation on markers of bone turnover that are not $\gamma$-carboxylated may be due to the relatively short duration of the study. However, Braam et al. (2003) did not see an effect on urinary Dpyr and serum BAP activity after phylloquinone supplementation for 3 years, even though, interestingly, the rate of bone loss at the femoral neck was significantly reduced (Braam et al. 2003).

It cannot be ruled out that, had the women been supplemented with $\mathrm{Ca}$ in addition to vitamin $\mathrm{D}$, the effect of a vitamin $\mathrm{K}$ supplement would have been different. Braam et al. (2003) report that vitamin $\mathrm{K}$ given as a supplement in addition to minerals and vitamin $\mathrm{D}$ had a more pronounced effect on bone loss over 3 years than mineral and vitamin D supplementation alone. However, it is not known whether the effect of vitamin $\mathrm{K}$ is dependent on $\mathrm{Ca}$ intake, and thus it should be emphasised that the present results apply to women with suboptimal $\mathrm{Ca}$ intakes.

In conclusion, the findings of the present study showed that increasing phylloquinone intake of postmenopausal women by 200 and $500 \mu \mathrm{g} / \mathrm{d}$ significantly increased the degree of $\gamma$-carboxylation of OC and, consequently, led to a reduction in concentrations of ucOC, an independent risk factor for osteoporotic fracture (Szulc et al. 1993, 1996; Vergnaud et al. 1997). The reduction in ucOC concentration (and ucOC:cOC ratio) achieved by phylloquinone supplementation, however, had no apparent modulating effect on bone turnover. This may be explained by an apparently adequate habitual intake of phylloquinone and it is possible that very large doses of phylloquinone are required to see a response. Therefore, further research is warranted to investigate the mechanisms of action of phylloquinone on BMD and fracture risk, as well as further clarification of the physiological and clinical relevance of submaximal $\gamma$-carboxylation of OC, including its role as a status indicator for vitamin $\mathrm{K}$ nutriture. This issue is of importance for further consideration of the dietary requirement for phylloquinone, as the findings of the present and other studies would suggest that usual dietary intakes of several population sub-groups provide inadequate phylloquinone to allow maximal $\gamma$-carboxylation of $\mathrm{OC}$.

\section{Acknowledgements}

The present study was carried out with financial support from the European Commission, Quality of Life, Fifth Framework Programme QLK1-1999-00752 'Optimal Nutrition towards Osteoporosis Prevention: Impact of Diet and Gene-Nutrient Interactions on Calcium and Bone Metabolism'. F. Hoffmann La-Roche Ltd, Basel, Switzerland is appreciated for providing the placebo and the phylloquinone-containing capsules and also for delivering the internal standard 2,3-dihydrophylloquinone used in the analysis of serum vitamin $\mathrm{K}$. We gratefully acknowledge Vivian Anker, Ella Jessen, and Hanne Lysdal Pedersen, Department of Human Nutrition, Centre for Advanced Food Studies, The Royal and Veterinary Agricultural University, Denmark for their excellent technical assistance and the volunteers who participated in the present study. Project manager Professor Britt-Marie Sandström, Department of Human Nutrition, Centre for Advanced Food Studies, The Royal and Veterinary Agricultural University, Denmark unfortunately passsed away after a long period of illness. She will be honoured, remembered, and missed by all her colleagues.

\section{References}

Becker W, Lyhne N, Pedersen AN, Aro A, Fogelhol M, Pedersen JI, Alexander J, Andersen SA, Meltzer HM \& Pórsdóttir I (2004) Nordic Nutrition Recommendations 2004 - Integrating Nutrition and Physical Activity, pp. 313-322. Copenhagen: Nord, Nordic Council of Ministers.

Bingham S \& Cummings JH (1983) The use of 4-aminobenzoic acid as a marker to validate the completeness of $24 \mathrm{hr}$ urine collection in man. Clin Sci 64, 629-635.

Binkley NC, Krueger DC, Engelke JA, Foley AL \& Suttie JW (2000) Vitamin $\mathrm{K}$ supplementation reduces serum concentrations of under- $\gamma$-carboxylated osteocalcin in healthy young and elderly adults. Am J Clin Nutr 72, 1523-1528

Binkley NC, Krueger DC, Kawahara TN, Engelke JA, Chappell RJ \& Suttie JW (2002) A high phylloquinone intake is required to achieve maximal osteocalcin $\gamma$-carboxylation. Am J Clin Nutr 76, $1055-1060$. 
Binkley NC \& Suttie JW (1995) Vitamin K nutrition and osteoporosis. J Nutr 125, 1812-1821.

Booth SL, Broe KE, Gagnon DR, Tucker KL, Hannan MT, McLean RR, Dawson-Hughes B, Wilson PWF, Cupples A \& Kiel DP (2003) Vitamin K intake and bone mineral density in women and men. Am J Clin Nutr 77, 512-516.

Booth SL, Lichtenstein AH, O'Brien-Morse M, McKeown NM, Wood RJ, Saltzman E \& Gundberg CM (2001) Effects of a hydrogenated form of vitamin $\mathrm{K}$ on bone formation and resorption. $\mathrm{Am} J$ Clin Nutr 74, 783-790.

Booth SL, Tucker KL, Chen H, et al. (2000) Dietary vitamin K intakes are associated with hip fracture but not with bone mineral density in elderly men and women. Am J Clin Nutr 71, 1201-1208.

Booth SL, Webb R \& Peters JC (1999) Assessment of phylloquinone and dihydrophylloquinone dietary intakes among a nationally representative sample of US consumers using 14-day food diaries. J Am Diet Assoc 99, 1072-1076.

Braam LA, Knapen MH, Geusens P, Brouns F, Hamulyak K, Gerichhausen MJ \& Vermeer C (2003) Vitamin $\mathrm{K}_{1}$ supplementation retards bone loss in postmenopausal women between 50 and 60 years of age. Calcif Tissue Int 73, 21-26.

Bügel S (2003) Vitamin K and bone health. Proc Nutr Soc 62, 839-843.

Calabresi E, Lasagni L, Franceschelli F, Bartolini L, Serio M \& Brandi ML (1994) Use of an internal standard to measure pyridinoline and deoxypyridinoline in urine (letter). Clin Chem 40, 336-337.

Colwell A, Russel RG \& Eastell R (1993) Factors affecting the assay of urinary 3-hydroxypyridinium crosslinks of collagen as markers of bone resorption. Eur J Clin Invest 23, 341-349.

Department of Health (1991) Calcium. In Dietary Reference Values for Food Energy and Nutrients for the United Kingdom. Report in Health and Social Subjects no. 41, pp. 150-157. London, UK: H.M. Stationery Office.

Douglas AS, Robins SP, Hutchison JD, Porter RW, Stewart A \& Reid DM (1995) Carboxylation of osteocalcin in post-menopausal osteoporotic women following vitamin $\mathrm{K}$ and $\mathrm{D}$ supplementation. Bone 17, 15-20.

Duggan P, Cashman KD, Flynn A, Bolton-Smith C \& Kiely M (2004) Phylloquinone (vitamin $\mathrm{K}_{1}$ ) intakes and food sources in 18-64year-old Irish adults. Br J Nutr 92, 151-158.

Feskanich D, Weber P, Willett WC, Rockett H, Booth SL \& Colditz GA (1999) Vitamin $\mathrm{K}$ intake and hip fractures in women: a prospective study. Am J Clin Nutr 69, 74-79.

Gijsbers BL, Jie KSG \& Vermeer C (1996) Effect of food composition on vitamin $\mathrm{K}$ absorption in human volunteers. Br J Nutr 76, 223-229.

Gundberg CM, Nieman SD, Abrams S \& Rosen H (1998) Vitamin K status and bone health: an analysis of methods for determination of undercarboxylated osteocalcin. J Clin Endocrinol Metab 83, 3258-3266.

Institute of Medicine (1997) Dietary Reference Intakes for Calcium, Phosphorus, Magnesium, Vitamin D, and Fluoride, pp. 71-145. Washington, DC: National Academies Press.

Institute of Medicine (2001) Dietary Reference Intakes for Vitamin A, Vitamin K, Arsenic, Boron, Chromium, Copper, Iodine, Iron, Manganese, Molybdenum, Nickel, Silicon, Vanadium and Zinc, pp. 162-196. Washington, DC: National Academies Press.

Knapen MHJ, Hamulyák K \& Vermeer C (1989) The effect of vitamin K supplementation on circulating osteocalcin (bone Gla protein) and urinary calcium excretion. Ann Intern Med 111, 1001-1005.

Knapen MHJ, Jie KSG, Hamulyák K \& Vermeer C (1993) Vitamin $\mathrm{K}$-induced changes in markers for osteoblast activity and urinary calcium loss. Calcif Tissue Int 53, 81-85.

Kuwada M \& Katayama K (1983) An improved method for determination of gamma-carboxyglutamic acid in proteins, bone and urine. Anal Biochem 131, 173-179.

McKeown NM, Jacques PF, Gundberg CM, Peterson JW, Tucker KL, Kiel DP, Wilson PWF \& Booth SL (2002) Dietary and nondietary determinants of vitamin $\mathrm{K}$ biochemical measures in men and women. J Nutr 132, 1329-1334.

Mølgaard C, Sandström B \& Michaelsen KF (1998) Evaluation of a food frequency questionnaire for assessing of calcium, protein and phosphorus intakes in children and adolescents. Scand J Nutr 42, 2-5.

Nishimoto SK \& Price PA (1985) The vitamin K-dependent bone protein is accumulated within cultured osteosarcoma cells in the presence of the vitamin K antagonist warfarin. J Biol Chem 260, 2832-2836.

Plantalech L, Chapuy MC, Guillaumont M, Chapuy P, Leclerq M \& Delmas DP (1990) Impaired carboxylation of serum osteocalcin in elderly women: effect of vitamin $\mathrm{K}_{1}$ treatment. In Osteoporosis, pp. 345-347 [C Christiansen and K Overgaard, editors]. Copenhagen: Osteopress.

Robins SP, Stead DA \& Duncan A (1994) Precautions in using an internal standard to measure pyridinoline and deoxypyrodinoline in urine (letter). Clin Chem 40, 2322-2323.

Ronden JE, Thijssen HH \& Vermeer C (1998) Tissue distribution of $\mathrm{K}$-vitamers under different nutritional regimens in the rat. Biochim Biophys Acta 1379, 16-22.

Sadowski JA, Hood SJ, Dallal GE \& Garry PJ (1989) Phylloquinone in plasma from elderly and young adults: factors influencing its concentration. Am J Clin Nutr 50, 100-108.

Schurgers LJ, Geleijnse JM, Grobbee DE, Pols HAP, Hofman A, Wittemann JCM \& Vermeer C (1999) Nutritional intake of vitamins $\mathrm{K}_{1}$ (phylloquinone) and $\mathrm{K}_{2}$ (menaquinone) in the Netherlands. J Nutr Environm Med 9, 115-122.

Shearer MJ (1997) The roles of vitamin D and K in bone health and osteoporosis prevention. Proc Nutr Soc 56, 915-937.

Shearer MJ (2000) Role of vitamin K and Gla proteins in the pathophysiology of osteoporosis and vascular calcification. Curr Opin Clin Nutr Metab Care 3, 433-438.

Sokoll LJ \& Sadowski JA (1996) Comparison of biochemical indexes for assessing vitamin $\mathrm{K}$ nutritional status in a healthy adult population. Am J Clin Nutr 63, 566-573.

Szulc P, Arlot M, Chapuy MC, Duboeuf F, Muenier PJ \& Delmas PD (1994) Serum undercarboxylated osteocalcin correlates with hip bone mineral density in elderly women. J Bone Miner Res 9, 1591-1595.

Szulc P, Chapuy MC, Meunier PJ \& Delmas PD (1993) Serum undercarboxylated osteocalcin is a marker of the risk of hip fracture in elderly women. J Clin Invest 91, 1769-1774.

Szulc P, Chapuy MC, Meunier PJ \& Delmas PD (1996) Serum undercarboxylated osteocalcin is a marker of the risk of hip fracture: a three year follow-up study. Bone 18, 487-488.

Thane CW, Paul AA, Bates CJ, Bolton-Smith C, Prentice A \& Shearer MJ (2002) Intake and sources of phylloquinone (vitamin $\mathrm{K}_{1}$ ): variation with socio-demographic and lifestyle factors in a national sample of British elderly people. Br J Nutr 87, 605-613.

Vergnaud P, Garnero P, Meunier PJ, Breart G, Kamihagi K \& Delmas PD (1997) Undercarboxylated osteocalcin measured with a specific immunoassay predicts hip fracture in elderly women: the EPIDOS study. J Clin Endocrinol Metab 82, 719-724.

Vermeer C \& Braam L (2001) Role of K vitamins in the regulation of tissue calcification. J Bone Miner Metab 19, 201-206.

Vermeer C, Gijsbers BLM, Craciun AM, Groenen-Van Dooren MM \& Knapen MH (1996) Effects of vitamin K on bone mass and bone metabolism. J Nutr 126, 1187S-1191S.

Vermeer C, Shearer MJ, Zittermann A, Bolton-Smith C, Szulc P, Hodges S, Walter P, Rambeck W, Stöcklin E \& Weber P (2004) Beyond deficiency: potential benefits of increased intakes of vitamin K for bone and vascular health. Eur J Nutr 5, 1-11.

Weber P (2001) Vitamin K and bone health. Nutr 17, 880-887.

World Health Organization (1994) Assessment of Fracture Risk and its Application to Screening for Postmenopausal Osteoporosis. Technical Report Series no. 843. Geneva: WHO.

Wu W, Bancroft JD \& Suttie JW (1996) Differential effects of warfarin on the intracellular processing of vitamin K-dependent proteins. Thromb Haemost 76, 46-52. 